\title{
Teleseismic depth estimation of the 2015 Gorkha-Nepal aftershocks
}

\author{
Jean Letort, ${ }^{1,2, *}$ Laurent Bollinger, ${ }^{2}$ Helene Lyon-Caen, ${ }^{1}$ Aurélie Guilhem, ${ }^{2}$ Yoann Cano, ${ }^{2}$ \\ Christian Baillard ${ }^{1}$ and Lok Bijaya Adhikari ${ }^{3}$ \\ ${ }^{1}$ Laboratoire de Géologie, Ecole Normale Supérieure/CNRS UMR 8538, PSL Research University, Paris F-75005, France.E-mail: jean.letort@ujf-grenoble.fr \\ ${ }^{2}$ CEA, CEA/DAM/DIF, Arpajon FR F-91297, France \\ ${ }^{3}$ National Seismological Centre, Department of Mines and Geology, Lainchaur, Kathmandu, Nepal
}

Accepted 2016 September 22. Received 2016 September 21; in original form 2016 March 31

\begin{abstract}
SUMMAR Y
The depth of 61 aftershocks of the 2015 April 25 Gorkha, Nepal earthquake, that occurred within the first $20 \mathrm{~d}$ following the main shock, is constrained using time delays between teleseismic $P$ phases and depth phases ( $p P$ and $s P$ ). The detection and identification of these phases are automatically processed using the cepstral method developed by Letort $e t$ al., and are validated with computed radiation patterns from the most probable focal mechanisms. The events are found to be relatively shallow $(13.1 \pm 3.9 \mathrm{~km})$. Because depth estimations could potentially be biased by the method, velocity model or selected data, we also evaluate the depth resolution of the events from local catalogues by extracting 138 events with assumed well-constrained depth estimations. Comparison between the teleseismic depths and the depths from local and regional catalogues helps decrease epistemic uncertainties, and shows that the seismicity is clustered in a narrow band between 10 and $15 \mathrm{~km}$ depth. Given the geometry and depth of the major tectonic structures, most aftershocks are probably located in the immediate vicinity of the Main Himalayan Thrust (MHT) shear zone. The mid-crustal ramp of the flat/ramp MHT system is not resolved indicating that its height is moderate (less than 5-10 km) in the trace of the sections that ruptured on April 25. However, the seismicity depth range widens and deepens through an adjacent section to the east, a region that failed on 2015 May 12 during an $M_{\mathrm{w}} 7.3$ earthquake. This deeper seismicity could reflect a step-down of the basal detachment of the MHT, a lateral structural variation which probably acted as a barrier to the dynamic rupture propagation.
\end{abstract}

Key words: Earthquake source observations; Seismicity and tectonics; Body waves.

\section{INTRODUCTION}

The M7.8 Gorkha earthquake hit Nepal on 2015 April 25 at 06:11:26 UTC (Adhikari et al. 2015), and devastated a large region at the foot of the Himalaya range, North of Kathmandu (e.g. Martin et al. 2015). The main shock partially ruptured a 120-km-long segment of the shallow dipping Main Himalayan Thrust (MHT), which marks the plate boundary between India and the Tibetan Plateau (Avouac et al. 2015; Grandin et al. 2015; Elliott et al. 2016). The rupture propagated eastward from the epicentre, located $75 \mathrm{~km}$ westnorthwest from the capital Kathmandu, and stopped $\sim 50 \mathrm{~s}$ later at a similar distance to the north-northeast of the capital according to Grandin et al. (2015; Fig. 1). The depth of the rupture process

*Now at: Université de Grenoble Alpes3bis, ISTerre, F-38000 Grenoble, France. was assumed to be constant around $15 \mathrm{~km}$ during the inversion of geodetic and seismological data (Grandin et al. 2015).

The main shock was followed by a large number of aftershocks distributed along the ruptured fault segment at mid-crustal depths (Adhikari et al. 2015; Bai et al. 2016). Hundreds of events with magnitude above 4.5 were detected during the first days after the main shock (Fig. 1) compared to less than 20 during the $5 \mathrm{yr}$ prior to the earthquake within the same area (according to the catalogue from the National Seismological Center, NSC). Seventeen days after the main shock, on May 12, an $M_{\mathrm{w}} 7.3$ event ruptured the eastern rim of the main shock rupture (e.g. Lindsey et al. 2015), and was followed by a dense aftershock sequence. Many of these seismic events were felt by the millions of inhabitants of the Kathmandu valley.

Constraining the depths of these early aftershocks is crucial. First, it should help associate these events to the Main Himalayan shear zone or to local geological structures, either in its hangingwall or footwall. Second, understanding the post-seismic behaviour of the 


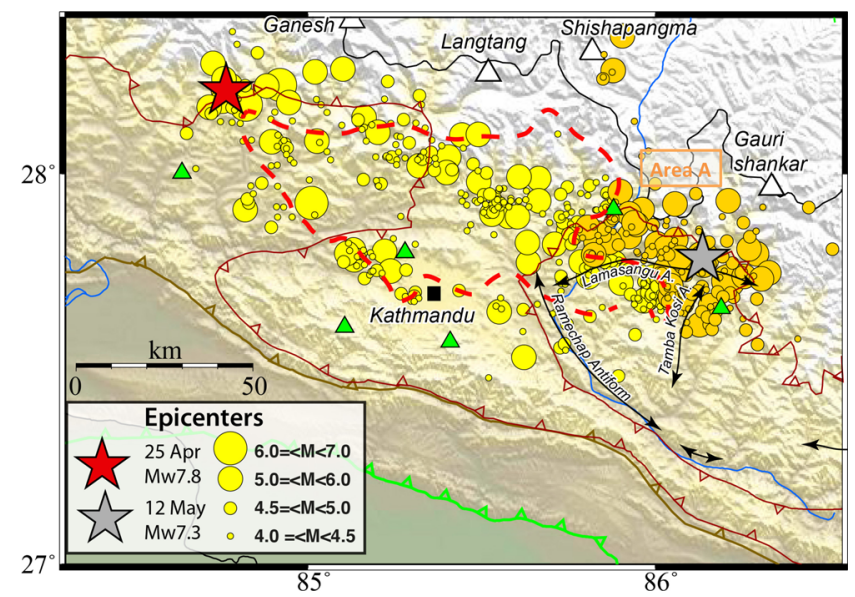

Figure 1. Map of the locations of the aftershocks (yellow and orange dots) sized by magnitudes that occurred in the $20 \mathrm{~d}$ following the Gorkha earthquake. The two stars show the position of the April 25 (red star) and the May 12 (grey star) main shocks. The red dash lines highlight the approximate position of the rupture rim of the main shock, derived from Grandin et al. (2015). The orange dots correspond to aftershocks located at the eastern rim of the April 25 rupture, this area is mentioned later in the discussion as the area A. The red, brown and green lines, respectively, indicate the Main Central Thrust (MCT), the Main Boundary Thrust (MBT) and the Main Frontal Thrust (MFT) which are the major thrust faults branching on the Main Himalayan Thrust (MHT) at depth. The green triangles are the locations of the stations from the Nepalese network, the National Seismological Center (NSC). The double headed black arrows indicate the positions of the major anticlines.

fault provides a unique opportunity to constrain possible lateral variations of the tectonic structures, which may control the main rupture.

However, in the absence of a dense local seismic network, depth estimation is often challenging. Trade-offs between depth and origin time estimations can be found, as well as possible biases related to crustal velocity heterogeneities. Hence, Bondár et al. (2004) showed that, except for very short distances (less than 10-20 km), the traveltime residuals associated to direct phases $(P g, P n$ and $P)$ are relatively insensitive to large event depth variation. Even though the absolute direct phase arrivals have little impact on depth resolution, the time delays between the arrivals of surface-reflected phases ( $p P, s P$, also called depth phases) and the direct $P$ phases contain useful information on the source depth. Such approach provides constraints on the event depths but remains difficult for smaller events $\left(M_{\mathrm{L}}<5.5\right)$ for which these depth phases are generally not detected.

Here, we select 108 aftershocks with $M_{\mathrm{L}}>4.5$ (Figs 2a and b), recorded at teleseismic distance, within a period of $20 \mathrm{~d}$ following the Gorkha main shock, and we detect depth phases ( $p P$ and $s P$ ) using the cepstral method described by Letort et al. (2015). We mainly use Comprehensive Test-Ban Treaty Organization (CTBTO) arrays that help global depth phase detections (Storchak et al. 2011). Such CTBTO arrays help improve the detection of depth phases for moderate $\left(4.5<M_{\mathrm{L}}<6.5\right)$ magnitude events at teleseismic distances (Letort et al. 2014).

After a drastic data selection optimized for the cepstral analysis, we select six arrays/stations (Fig. 2c). We discuss the uncertainties on depth estimations, and we compare our results to published depths determined by local seismic networks. This is done by analysing the local depth estimations based on phase picks extracted from the Nepalese bulletin (Adhikari et al. 2015) and by investigating the effects of the velocity model. We finally discuss the structural and seismotectonic implications of the results.

\section{TELESEISMIC DEPTH ESTIMATION USING THE CEPSTRAL METHOD}

The time delay between the direct $P$ wave and a depth phase ( $p P$ or $s P$ ) in a teleseismic record constitutes one of the best ways to determine hypocentre depths (Engdahl et al. 1998; Bondár \& Storchak 2011). However, these phases are often difficult to identify for small to moderate magnitude events $\left(M_{\mathrm{L}}<5.5\right)$ as they are often mixed with other phases in the $P$-coda (Bondár \& Storchak 2011). For most events of the Gorkha aftershock sequence, depth phase picking is a particularly challenging exercise (Fig. S1, Supporting Information). Indeed, these events occurred in a complex area with important topographic effects and significant heterogeneities in the velocity structure due to the geometry of the Himalayan range (Monsalve et al. 2008; Nábelek et al. 2009). Hence, $p P$ and $s P$ waves are often arriving at the time of other waves generated by this complex source environment (Figs 3 and S1, Supporting Information). To decrease epistemic uncertainties, we refrain from manually picking these phases (Engdahl et al. 1998), and we prefer to use an automatic method to detect the main phases arriving a few seconds after the direct $P$ wave in a teleseismic record, the cepstral analysis (see Section 2.2).

\subsection{Data selection and processing}

The 108 aftershocks are selected from the 172 aftershocks with local magnitude $\left(M_{\mathrm{L}}\right)$ between 4.5 and 6.5 of the Nepalese bulletin (Adhikari et al. 2015). They are selected when at least four direct $P$-wave arrivals are detected by the teleseismic networks, considered for this study (mostly CTBTO arrays). Because of the complexity of the teleseismic records and the relatively low magnitude range ( $4.5<M<6.5)$ of the events considered (Fig. 2b), one drastic selection of the stations among the whole set of requested stations (extracted from IRIS via the FDSN network codes, networks II, IU, Geoscope and from CTBTO) is necessary. Only six arrays/stations (BRTR, FINNES, TORD, KSRS, GERES for the CTBTO arrays and LSZ for IRIS) are selected (Fig. 2c). These six arrays and station have been chosen as a compromise between a good azimuthal distribution and the quality of the signal-to-noise ratio (SNR) of the $P$-coda in the $1-3 \mathrm{~Hz}$ passband. Other stations presenting some very good SNR have been rejected (i.e. stations ILAR and KDAK) because of potential core-reflected phases (PcP, $\mathrm{pPcP}$, etc.). The cepstrum analysis is then blindly applied on $1-3 \mathrm{~Hz}$ bandpass filtered vertical components, starting $5 \mathrm{~s}$ before the theoretical $P$-wave arrival until $30 \mathrm{~s}$ after. When arrays are considered, all stations of the array are stacked to increase the SNR prior to the analysis.

\subsection{Cepstrum analysis}

The cepstral analysis studies the spectral holes in the shape of a signal spectrum (Letort et al. 2015) and estimates the time delay between direct $P$ wave and dominant reflections in the $P$-coda (Fig. 3). Basically, a (power) cepstrum is defined as the norm of the inverse Fourier transform of the logarithm of the norm of the Fourier transform of a signal $S_{\text {sta }_{i}}(t)$, see eq. (1)

Cepstrum $_{\text {sta }_{i}}(t)=\mid \mathrm{TF}^{-1}\left(\log \left(\mid \mathrm{TF}\left(S_{\text {sta }_{i}}(t) \mid\right)\right) \mid\right.$. 
(a)
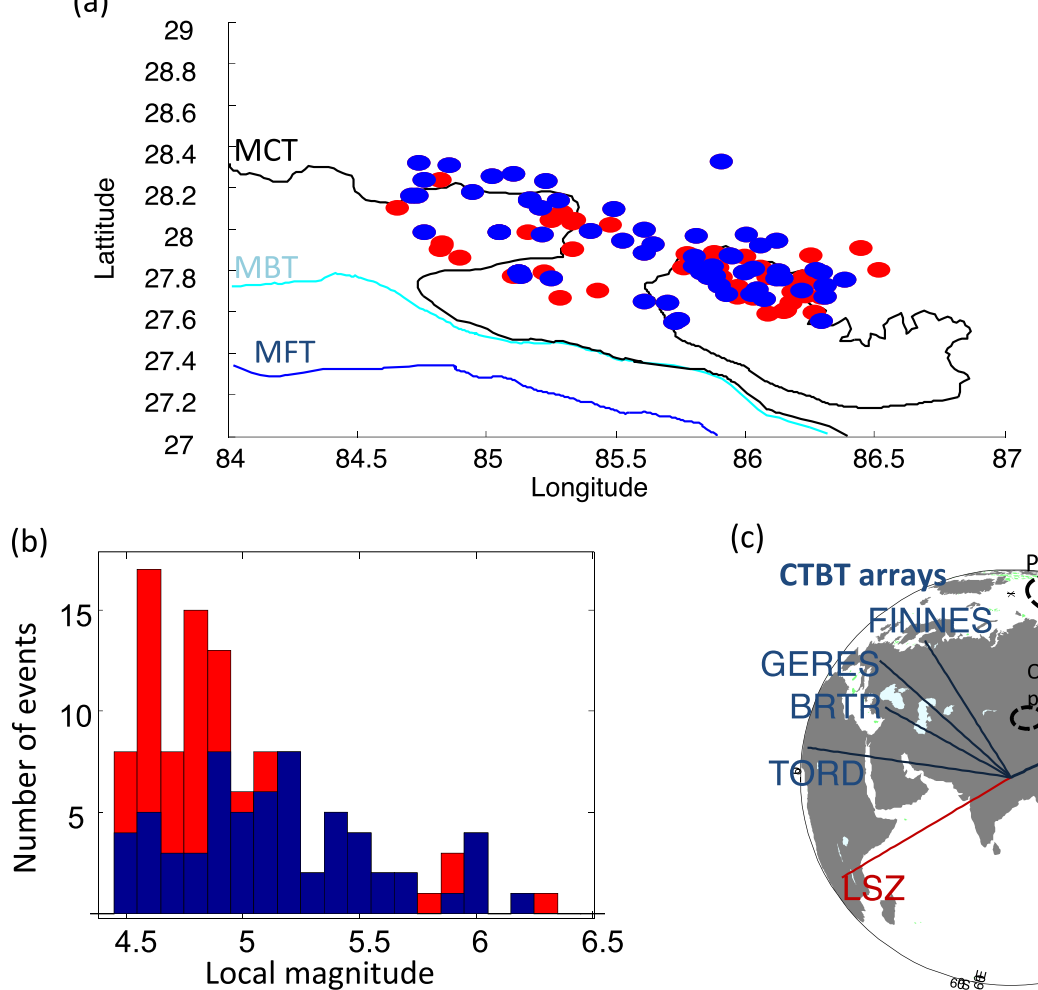

(c)

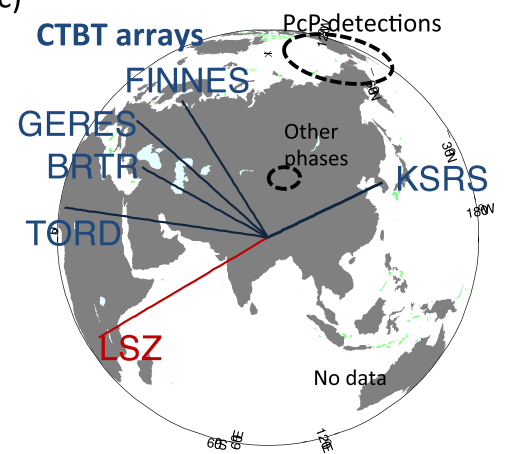

Figure 2. Data used for this study. (a) Map of the 108 selected aftershocks occurring in the $20 \mathrm{~d}$ following the Gorkha main shock with magnitude larger than 4.5. All events are in red unless their depth is estimated by cepstral analysis (blue). (b) Distribution of the local magnitudes $\left(M_{\mathrm{L}}\right)$ of the 108 selected events (red) and those for which we estimate a depth at teleseismic distance (blue). (c) Location of the five CTBTO arrays (blue) and the IRIS station (red) used in the analysis.

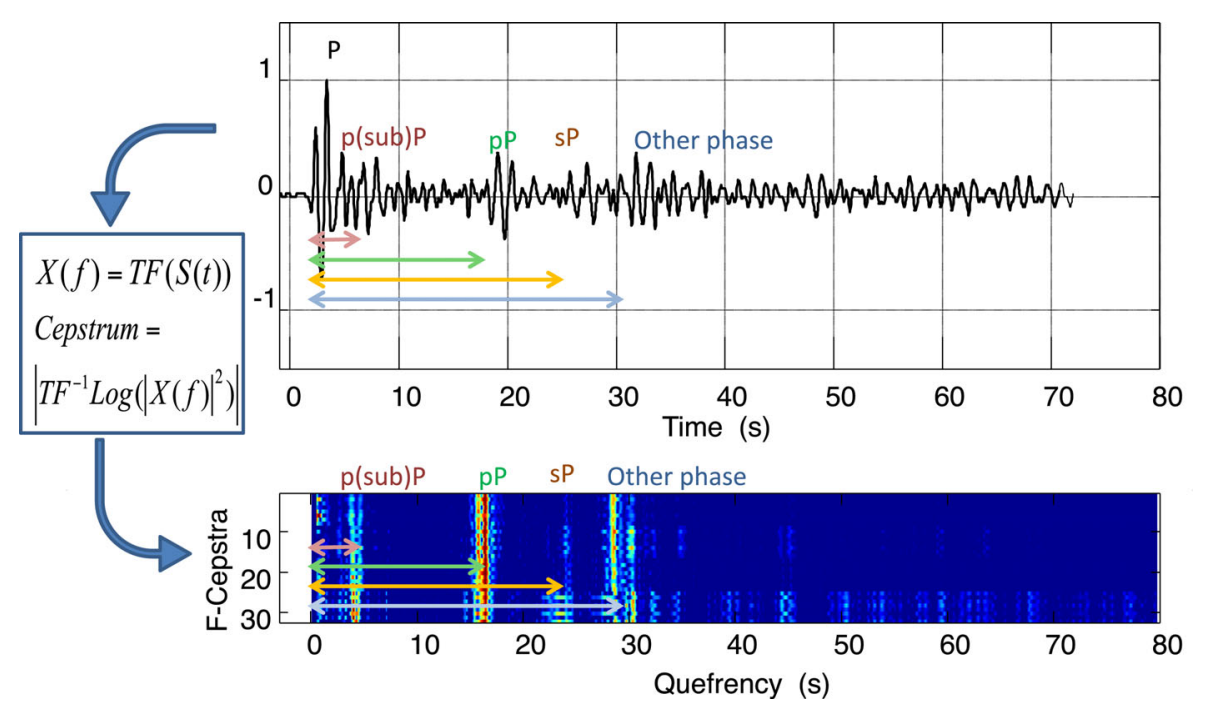

Figure 3. Figure modified from Letort et al. (2015) for an earthquake at $55 \mathrm{~km}$ deep in Guerrero (Mexico), recorded at TRQA (Argentina), at a distance of $67^{\circ}$. Illustration of the cepstral method on a selected teleseismic record (top) and its corresponding result (bottom). A time window (top) is first fixed around the direct $P$ arrival, incorporating the $P$-coda composed by different reflected waves (among them $p P$ and $s P$ ). We assume that these reflected waves behave as 'echoes' of the direct $P$ wave. The cepstral operator is used to detect these echoes. It uses different frequency bands and time window lengths. The cepstra functions (bottom) are almost null everywhere, except for peaks at the time delays (quefrencies) between the $P$ and the main echoes, assumed to be $p P$ and/or $s P$.

An echo of a phase in a waveform creates a modulation (a cosine) of the spectrum in the Fourier domain. This modulation has a periodicity proportional to the inverse of the delay between the main phase and its echo. Applying an inverse Fourier transform to the spectrum gives a peak related to this modulation (thus a peak for the delay between the two phases). The cepstrum $\operatorname{Cepstrum}_{\text {sta }_{i}}(t)$ is hence a function of time delays (quefrencies) that is null everywhere except for one or more peak(s) corresponding to dominant echo(es) in the signal (Fig. 3). The method has been tuned to detect small events in noisy records and to focus on one main echo by reducing the impact of other arrivals in the cepstrum analysis (Letort et al. 2015). For earthquakes, the main reflection/echo observed after the 
(a)

(d)
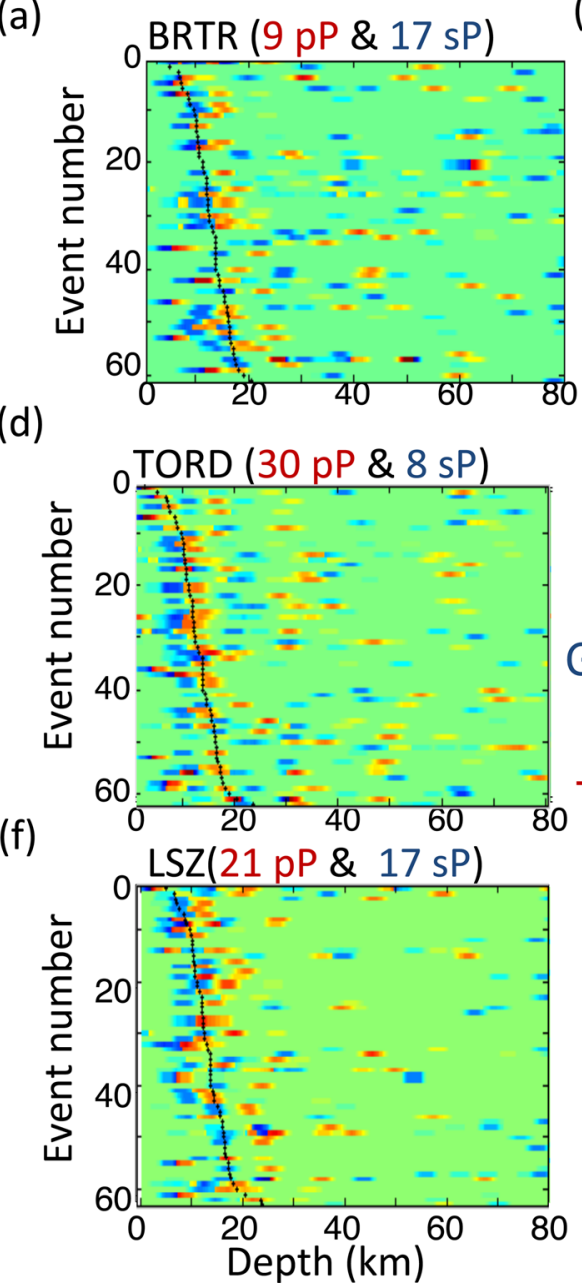

(b)

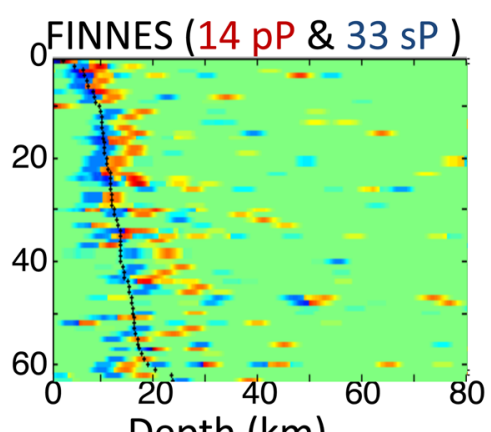

(g)

Depth $(\mathrm{km})$

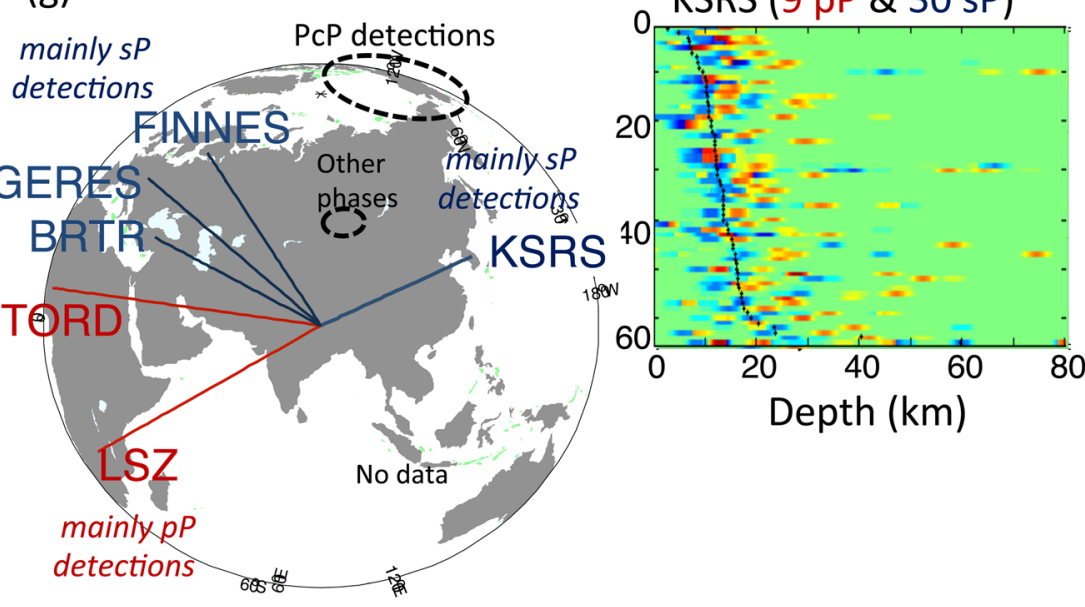

Legend for $(a),(b),(c),(d),(e),(f)$ :

(c)

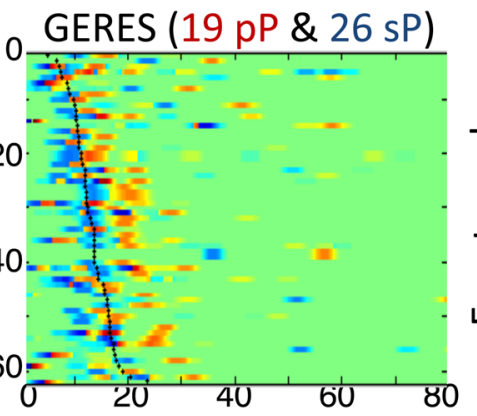

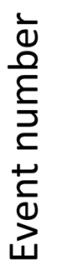

Figure 4. Depth solutions derived from the cepstral peaks for all selected events using the five teleseismic arrays: (a) BRTR, (b) FINNES, (c) GERES, (d) TORD, (e) KSRS and (f) the station LSZ, at teleseismic distances. The delays related to the main echoes deduced from the cepstral analysis are converted to equivalent depth probability peaks assuming these delays are due to $P, s P$ arrivals (peaks in blue) or to $P, p P$ arrivals (peaks in red). The dark dots show the final depths estimated for each event. Comparison between the black dots and the blue and red peaks informs on the dominant depth phase (either $p P$ or $s P$ ) for each event. (g) Summary of the detections at each station. Stations that mainly detected $s P$ phases from the Nepalese sequence are shown in blue and in red, when $p P$ phases are dominantly found.

$P$ wave is generally a $p P$ or $s P$ phase depending on the radiation pattern at the source (Pearce $\&$ Rogers 1989). Indeed, reflections at the free surface are often more energetic than reflections on other interfaces.

First, if one assumes that the main echo is due to a $p P$ phase, the unique relationship between $P-p P$ delay $(t)$, distance station event and depth, $d$, given by the ak135 global velocity model: depth $=$ $T_{p P}(t)$ allows to convert this function into an equivalent function of depth $C_{p P \_s t a}$ (depth), where the peak is related to the depth of the event (assuming $p P$ detection).

$C_{p P_{-} \text {sta }_{i}}($ depth $)=T_{p P}\left[\operatorname{Cepstrum}_{\text {sta }_{i}}(t)\right]$.

Because the region we study is characterized by major topographic variations, the cepstrum $C_{p P_{-} \text {sta }_{i}}$ (depth) is corrected by subtracting the altitude of the estimated reflection point of the $p P$ phase (more precisely, averaging the altitude of the topography grid around $3 \mathrm{~km}$ of the reflection point, assuming to be the Fresnel zone). In a second time, the cepstrum function can be converted into another equivalent function of depth using the relationship between $P-s P$ delay and depth (eq. 3)
$C_{S P \_ \text {sta }_{i}}($ depth $)=T_{S P}\left[\right.$ Cepstrum $\left._{\text {sta }_{i}}(t)\right]$.

The two functions are estimated for each station $\mathrm{sta}_{i}$, normalized and summed, and give a final depth probability curve $C_{(p P+s P)_{\text {sta }}}$ assuming either $p P$ or $s P$ arrivals:

$C_{(p P+s P)_{\text {sta }} i}=\left|C_{p P P_{-} \mathrm{sta}_{i}}+C_{s P_{\text {sta }} i}\right| * \operatorname{sign}\left(C_{p P_{\mathrm{sta}_{i}}}-C_{s P_{\mathrm{sta}_{i}}}\right)$.

The estimated functions are represented in Fig. 4 for each station and array. In order to keep information on the type of depth phase $\left(p P\right.$ or $s P$ ) used to derive the depth, $C_{(p P+s P)_{-} \text {sta }_{i}}$ is given with positive values when the peaks are mainly related to $p P$ detections (red peaks in Fig. 4) and with negative values when related to $s P$ detections (blue peaks in Fig. 4).

Depth candidates associated to a phase detection are then ex-

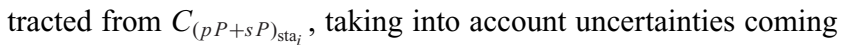
from the velocity model, as follows:

IsPhase $_{\text {sta }_{i}}(D)$

$=\rightarrow 1$ if $\max \left(\left|C_{(p P+s P)_{\mathrm{sta}_{i}}}([D-1.5 D+1.5])\right|\right)>0.8$

$\rightarrow 0$ Otherwise . 

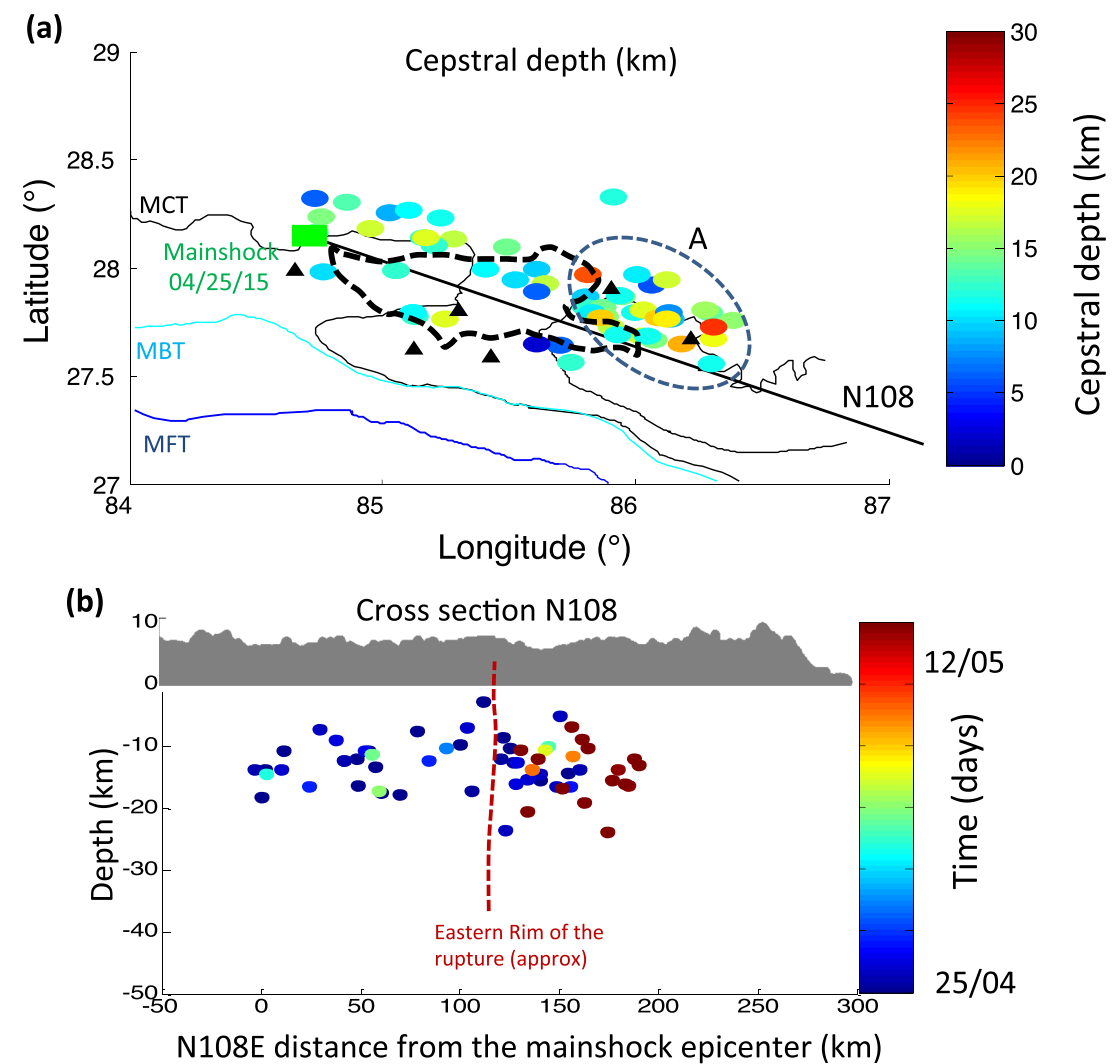

Figure 5. (a) Map view showing the final depth estimations from cepstral analysis. Only events (dots) with at least three consistent depth phase detections among the six station/arrays are represented. The black dash contour represents the approximate position of the rim of the April 25 main shock rupture derived from Grandin et al. (2015), and the black full line represents the $\mathrm{N} 108^{\circ}$ axis and the square the location of the epicentre of the main chock. The area A is the area described in Fig. 1 at the eastern rim of the rupture. (b) Cross-section of the events pictured in (a), for the projection along the N108 axis, parallel to the Himalayan range. The colour corresponds to the temporal occurrence of the events after the main shock: the aftershocks of the April 25 main shock are shown in blue, and the aftershocks after the second May 12 main event are shown in red. Note that the area A in (a) highlights events at the eastern part of the April 25 rupture, and where the aftershocks of the May 12 located.

Finally, the final depth $(D f)$ corresponds to the one that has the maximum number of phase detections among the six stations, hence, the maximum of $\sum_{\text {sta }_{i}}$ IsPhase $_{\text {sta }_{i}}(D)$. We impose a minimum of three stations to identify a depth phase arrival for the same depth in order to validate the final cepstrum depth. Using this approach, we successfully estimate the depth of 61 events out of the 108 selected (Figs 5a, b and Table S1, Supporting Information).

\subsection{Validation of the depth estimations through the analysis of the detected phases}

Uncertainties on depth estimation depend on the reliability of the velocity model as well as on the efficiency, reliability and proper identification of the seismic phases $(p P$ or $s P$ ). As demonstrated by Letort et al. (2015), the cepstrum can efficiently extract echoes even in noisy records. The cepstrum of the $P$-coda (without the direct $P$ wave) can also be subtracted from the whole cepstrum $(P+P$-coda $)$ to avoid peaks coming from echoes of phases interacting together in the $P$-coda. Such procedure is used in this study and gives confirmation that the observed cepstrum peaks are reliably associated with reflections of the $P$ wave, even in a case of a weak $P$-wave arrival (Letort et al. 2015). We assume such reflections to be $p P / s P$ phases. However, other reflections of the direct $P$ wave, in the near-source environment are detected (Fig. 4). The quality of the depth estimation is based on the detection redundancy from different azimuths, and in particular, on the detection of disassociated $p P$ and $s P$ arrivals that are related to the azimuthal source radiation. From eqs (3) and (4), applied to the final depth $D f$, the type of phase $(p P$ or $s P$ ) detected to constrain the depth can be estimated, see eqs (6) and (7)

$$
\begin{aligned}
p P \text { detection } & =1 \text { if } \operatorname{IsPhase}_{\text {sta }_{i}}(D f) \\
& =1 \text { and } C_{(p P+s P)_{\text {sta }_{i}}}(D f)>0 \\
s P \text { detection } & =1 \text { if } \operatorname{IsPhase}_{\text {sta }_{i}}(D f) \\
& =1 \text { and } C_{(p P+s P)_{\text {sta }_{i}}}(D f)<0 .
\end{aligned}
$$

In Fig. 4, the number of detected $p P$ and $s P$ are summarized. We find that FINNES predominantly detected $s P$ phases (33 $s P$ against $14 \mathrm{pP}$ ). On the other hand, KSRS, and in a weaker proportion for BRTR and GERES as well as TORD and LSZ, are dominated by $p P$ detections ( $30 p P$ against $8 s P$ for TORD slightly less for LSZ). This relative stability of the detection types indicates a similar radiation pattern for a significant number of the studied sources.

The prediction of the wave radiation pattern for a given focal mechanism provides estimations on the relative amplitudes of the depth phases. Focal mechanisms are thus a very useful tool to validate the automatic depth phase detection which controls the depth estimation. Unfortunately, little information on the fault plane solutions of the Gorkha aftershocks is available. Only 10 events have moment tensor solutions in the GCMT catalogue. Even though this 


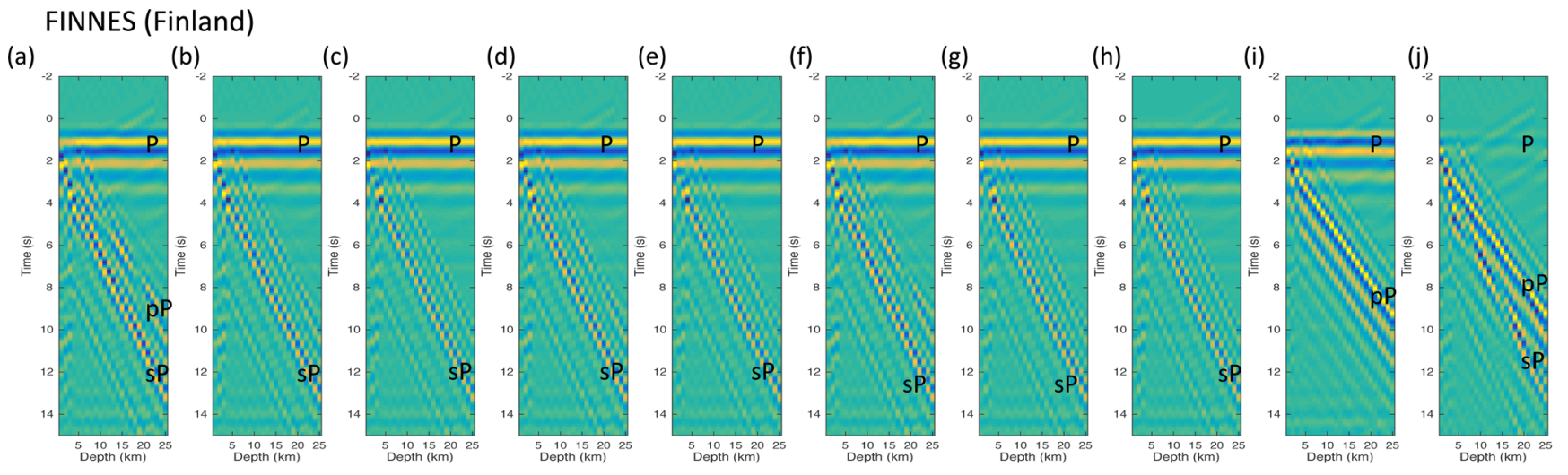

(a')

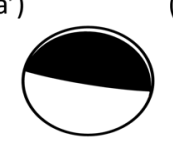

(b')

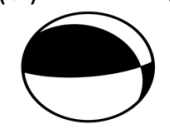

(c')

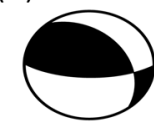

(d')

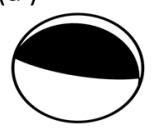

(e')

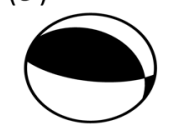

(f')

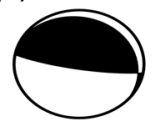

(g')

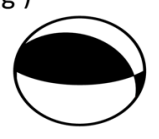

(h')

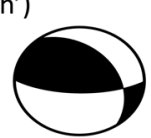

(i')

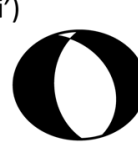

(j')

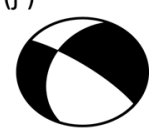

TORD (Niger)

(a")

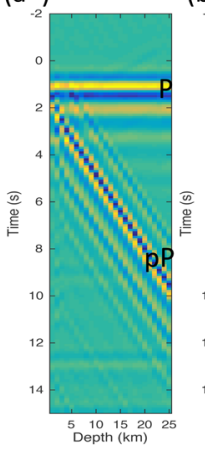

$\left(b^{\prime \prime}\right)$

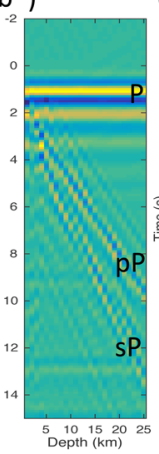

$\left(c^{\prime \prime}\right)$

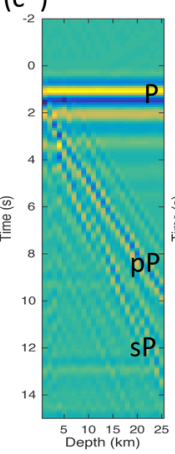

$\left(d^{\prime \prime}\right)$

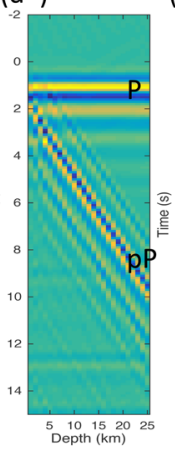

$\left(\mathrm{e}^{\prime \prime}\right)$

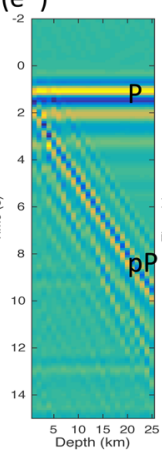

$\left(f^{\prime \prime}\right)$

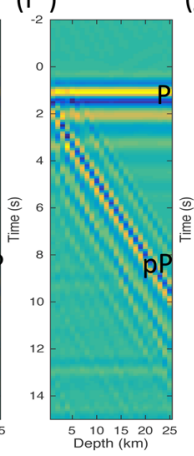

$\left(\mathrm{g}^{\prime \prime}\right)$

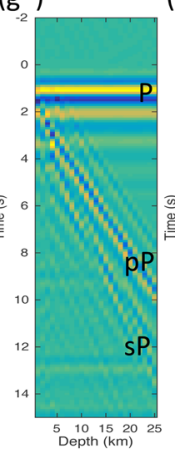

$\left(\mathrm{h}^{\prime \prime}\right)$

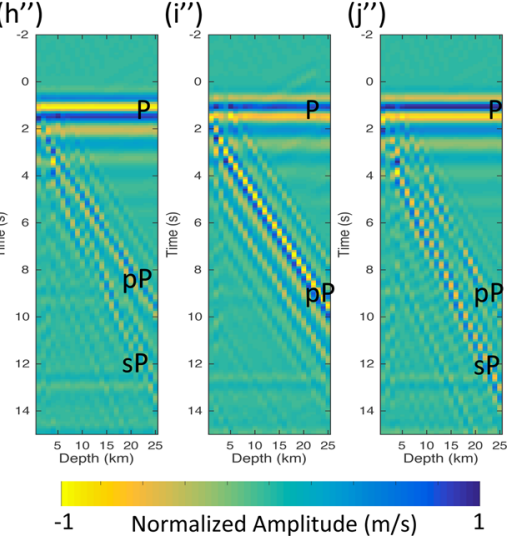

Figure 6. Simulations for 10 point-source mechanisms for a depth varying between 2 and $25 \mathrm{~km}$ with an increment of $1 \mathrm{~km}$. (a)-(j) are the normalized waveforms simulations for the array FINNES (Finland) for the 10 GCMT mechanisms $\left(\left(a^{\prime}\right)-\left(j^{\prime}\right)\right)$ for the main aftershocks that are available at the time of the study. $\left(\mathrm{a}^{\prime \prime}\right)-\left(\mathrm{j}^{\prime \prime}\right)$ are the simulations for the station TORD (Niger). Note the larger number of generated $p P$ phases (comparing to $s P$ phases) from the simulations for TORD. For FINNES, simulations show the generation of more $s P$ than $p P$.

number is small with regards to the number of the studied aftershocks, the GCMT solutions bring an overview of the possible mechanisms one can expect for this sequence (Fig. 6a).

Based on the GCMT solutions, simulations are performed for sources at depth varying between 2 and $25 \mathrm{~km}$ (Fig. 6). The 10 GCMT focal mechanisms are investigated for different epicentre locations of the source (only one source location is represented in Fig. 6, results are similar for the other source positions). The source duration is fixed at $0.5 \mathrm{~s}$, and the moment magnitude $M_{\mathrm{w}}$ is considered to be 5 . Synthetics are built using standard ray techniques following Bouchon (1976), Vallée et al. (2003) and Vallée (2004). Crust effects are taken into account by the reflectivity method of Mueller (1985), for both source and receiver. The mantle propagation was deduced from the IASPEI91 traveltime model (Kennett $\&$ Engdahl 1991) with a $t^{*}$ of $0.6 \mathrm{~s}$ (Lundquist \& Cormier 1980). Simulations point out stronger $s P$ than $p P$ phases at FINNES while at TORD, $p P$ are stronger than $s P$ (Figs $6 \mathrm{~b}$ and $\mathrm{c}$ ). This corroborates the observations from the cepstral analysis and leads to increasing confidence in the depth estimations using this approach. It further indicates that the focal mechanisms for a significant part of the studied aftershocks are relatively similar to one another. However, careful moment tensor studies of the aftershocks could help confirm this trend, while in the same time, validate our depth estimations.

\section{RESULTS AND COMPARISON WITH LOCAL/REGIONAL DEPTH ESTIMATIONS}

\subsection{Local depth estimations}

The Nepalese Department of Mines and Geology in charge of the earthquake monitoring in the region detected and located the 2015 Gorkha-Nepal aftershocks using their operational location procedures (Adhikari et al. 2015). However, these preliminary depths are often fixed during the procedure because of the lack of depth resolution due to both station coverage and instabilities related to inappropriate, or too simplistic, velocity model used in the inversion (i.e. here, a 1-D layered velocity model). In order to locate the events and to study the stability of the locations, Adhikari et al. (2015) investigated two inversion procedures mixing two inversion methods (linear and stochastic) and two velocity models. The first procedure uses a linear inversion, derived from Geiger (1912) and the Pandey (1985) 1-D velocity model, leading to the 
(a)

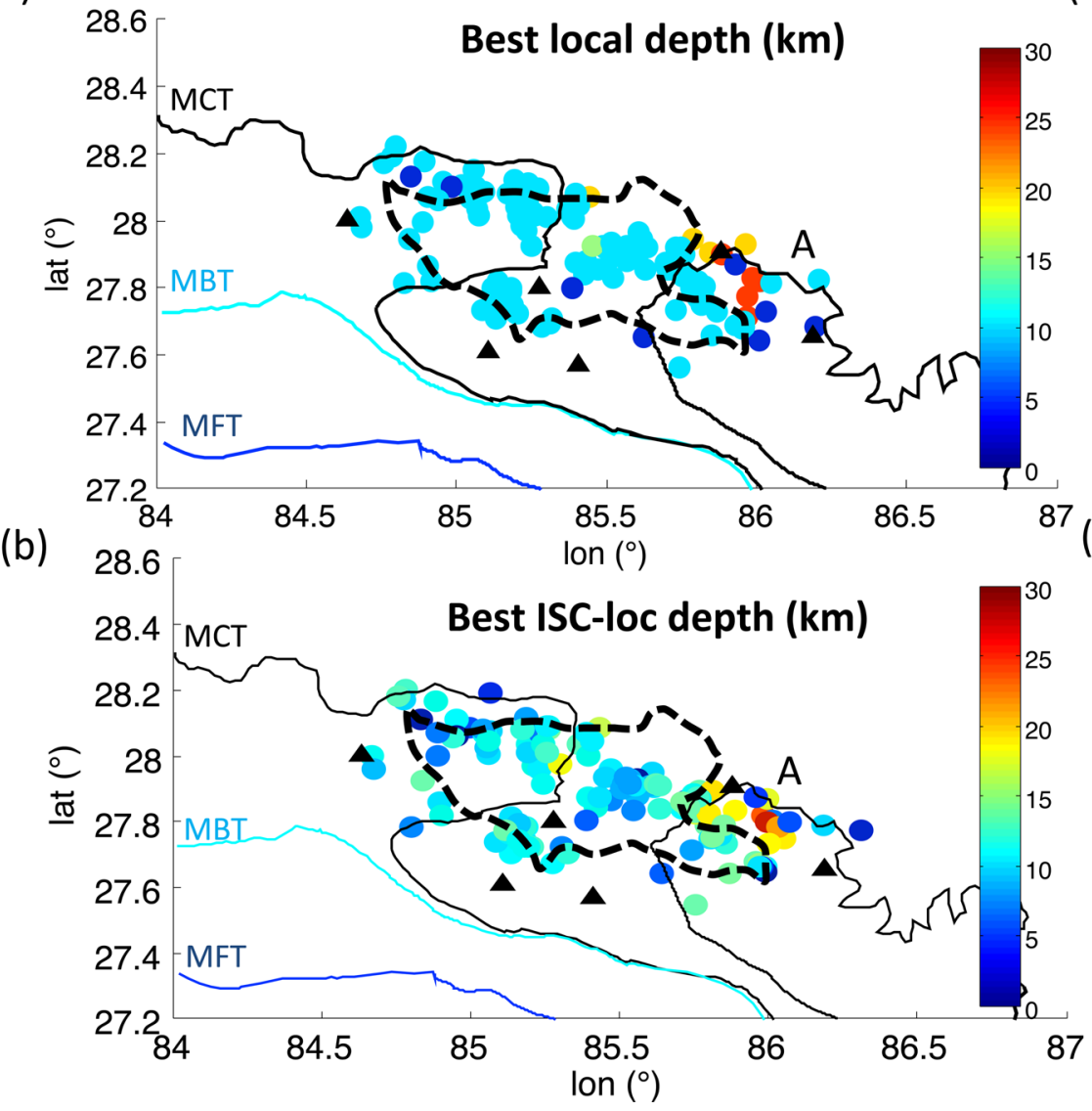

(c)

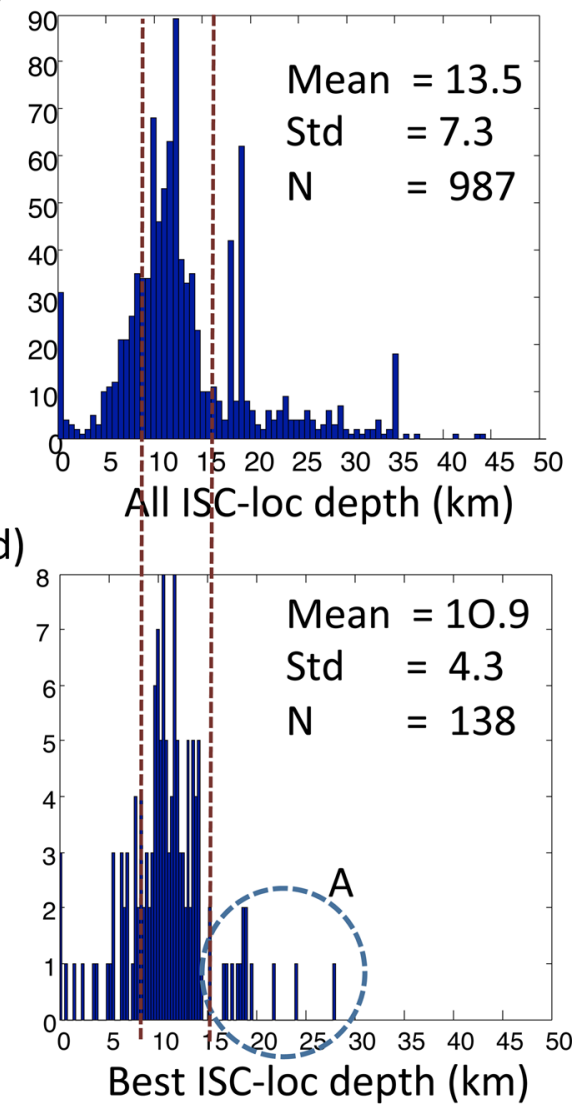

Figure 7. (a) Comparison of event depths from the local (Adhikari et al. 2015) and (b) the relocated catalogues (ISC-loc + RSTT model) using $P$ and $S$ regional phase arrivals reported in the local Nepalese seismic bulletin (Adhikari et al. 2015), between 2015 April 25 and 2015 May 14 . The dashed line corresponds to the extent of the rupture estimated by Grandin et al. (2015). (c) and (d) Depth distribution from the RSTT-ISCloc relocation for all events from 2015 April 25 to 2015 May 14 and from the event depths constrained from the RSTT-ISCloc relocation, respectively. The average depth varies between (c) and (d). Note in (c) the presence of default depth used by the ISCloc localization (10 and $35 \mathrm{~km})$.

hereafter named 'local catalogue'. Depth values can be fixed in this inversion procedure. The second approach uses the ISClocator (Bondár \& Storchak 2011) and the RSTT velocity model, which is a 3-D model including regional phase traveltime corrections (Myers et al. 2010), leading to the hereafter named 'relocated catalogue'. For the $20 \mathrm{~d}$ after the main shock, the average depths from the local and the relocated catalogue are, respectively, $11.1 \pm 5.5 \mathrm{~km}$ and $13.5 \pm 7.3 \mathrm{~km}$. The difference between these two catalogues $(2.5$ $\pm 4 \mathrm{~km}$ ) could partially be explained by differences in the velocity models but is also highly impacted by fixed depth values $(2,10,20$ and 30) in the first inversion process (Adhikari et al. 2015).

To better investigate the differences in the earthquake location, we prefer to focus on the events having the best depth estimations as the whole data set can be biased by poorly constrained events. We thus select events from the local catalogue between April 25 and May 14. Three empirical criteria have been chosen to assess depth resolution. Every event is required to meet all three criteria before being selected. A first criterion is the detection of at least one phase $(P$ or $S$ ) reported at a station close to the source (less than $50 \mathrm{~km}$ from the source). This minimum distance is quite large, compared to other depth resolution criteria based on epicentral distance (varying generally around 20-30 km, Gomberg et al. 1990; Bondár \& Storchak 2011). A second criterion imposes the presence of at least six $P$ and six $S$ phases at six different stations at regional distance with an rms below $0.5 \mathrm{~s}$ for the $S$-wave arrival. This corresponds to a modification of the Bondár \& Storchak (2011) criterion for depth resolution (i.e. five $P$ - and five $S$-phase detections). The choice of $\operatorname{six} S$-phase detections instead of five, and the use of the rms criteria should help reduce the possible influence of wrong picks. Finally, a third criterion concerns the azimuthal gap that has to be less than $300^{\circ}$. In a narrow azimuthal coverage, the trade-off between depth, origin time and location can be important. From 987 events reported in the catalogue, 138 satisfy these three criteria (when using the RSTT-ISC locator localization procedure).

When comparing the best depth estimations coming from the two procedures, the difference between the two catalogues $(0.8$ $\pm 3.5 \mathrm{~km}$ ) is now smaller (Fig. 7). However, note the remaining presence of several default depths used in the local catalogue (i.e. 10 and $30 \mathrm{~km}$ ). The average depth is now $10 \mathrm{~km}$ for the local catalogue and using the RSTT relocation, the average depth decrease from 13.5 to $10.9 \mathrm{~km}$ (Figs $7 \mathrm{c}$ and d). Thus, these two studies agree to point out that the seismicity clusters mainly around $10-15 \mathrm{~km}$ depth and extends deeper in the eastern rim of the rupture (zone A in Figs $7 a$ and $b$ ).

\subsection{Regional depth estimation results}

We then compare our results to depth estimations obtained at regional/teleseismic distance using an array at the Nepalese/Chinese 
(a)

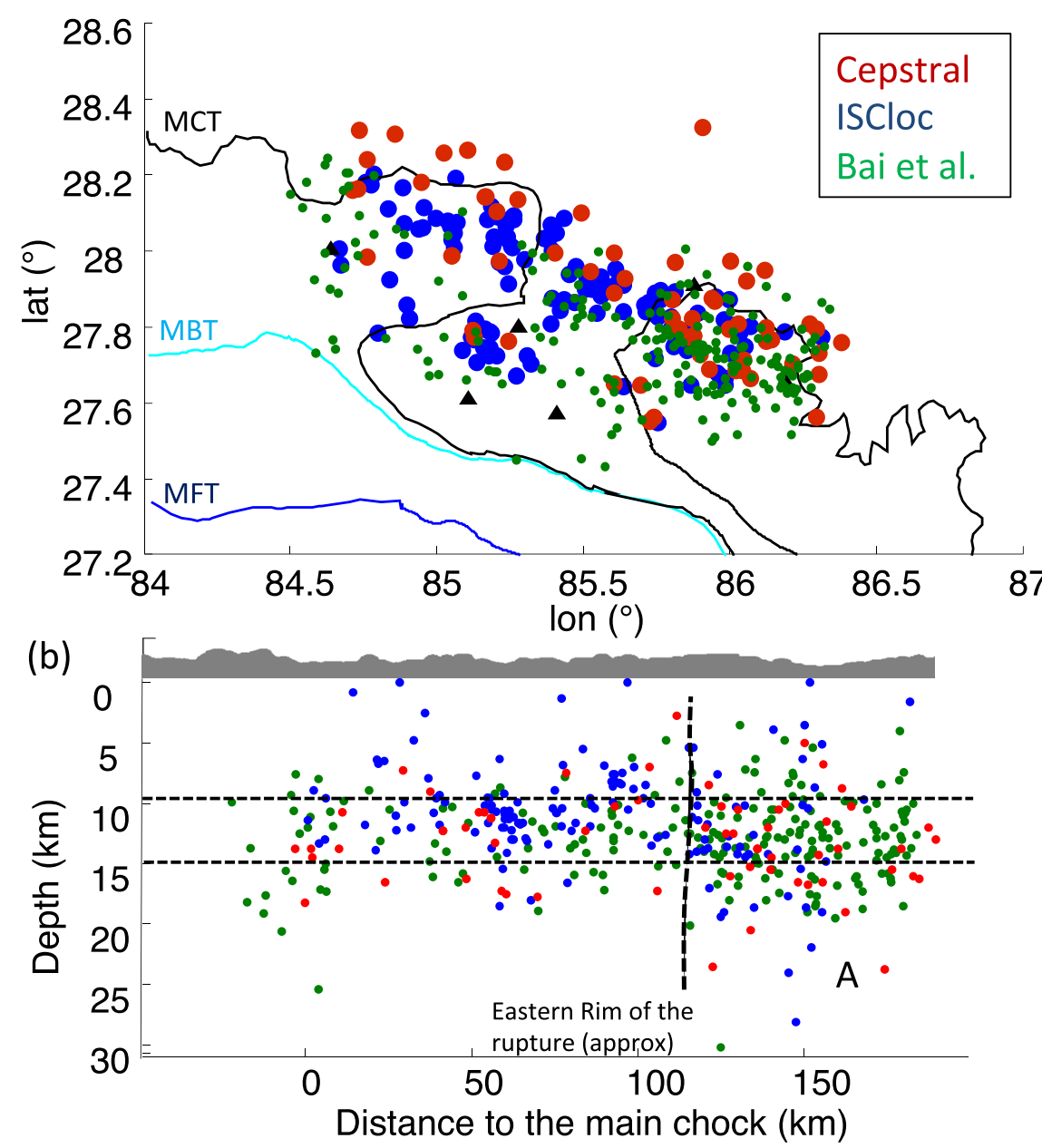

(c)

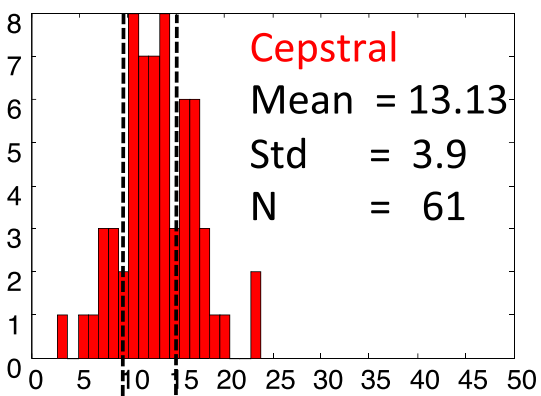

(d)

(e)

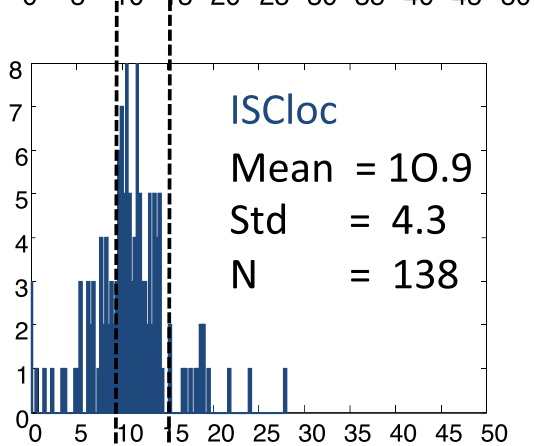

Figure 8. Comparison of depth estimations between different approaches. (a) Locations of the events according to the three catalogues (the relocations using the RSTT model in blue, the Bai et al. (2016) regional/teleseismic relocation in green, and the teleseismic analysis of the depth phase arrivals in red between April 25 and May 14). (b) Representation of the depth estimations along the N108 cross-section. (c)-(e) are the associated depth distributions.

border (Bai et al. 2016). Bai et al. (2016) used a relative relocation procedure and 172 depth phase detections to constrain the depth of the largest aftershocks. Fig. 8 shows that their average event depth, within the first $20 \mathrm{~d}$ of the seismic crisis, is $12.9 \pm 3.5 \mathrm{~km}$. This value is close to our teleseismic average depth estimation $(13.1 \mathrm{~km})$. The difference between the two catalogues is only $0.1 \pm 5.0 \mathrm{~km}$ for the 42 common events.

\subsection{Comparing teleseismic depth with local and regional depth estimates}

The 61 events, for which teleseismic depths are determined, are clustered between 10 and $15 \mathrm{~km}$, with an average depth of $13.1 \pm$ $3.9 \mathrm{~km}$ (Figs 5 and 8b). Aftershocks appear to be confined between 10 and $20 \mathrm{~km}$ within the first $100 \mathrm{~km}$ from the main shock epicentre (Fig. 5b). Deeper events reaching depths up to $25 \mathrm{~km}$ are observed at the eastern end of the rupture, at distance greater than $100 \mathrm{~km}$ from the epicentre. This eastern area (A) corresponds to the location of the second major earthquake on 2015 May 12.

When comparing the local depths (average $10.9 \mathrm{~km}$ ) with the teleseismic depths (average $13.1 \mathrm{~km}$ ), a bias is observed. The direct comparison between these average values is difficult because only four events are common to all catalogues (Table 1). Regarding these four events, the depth estimation varies from $11-12$ to $18-20 \mathrm{~km}$ depending on the catalogues and methods. Indeed, their theoretical depth phase arrivals computed from the teleseismic depth estimations better explain the observed phase arrivals on the teleseismic records (Fig. S2, Supporting Information), and provide a higher confidence level to our teleseismic depth estimations.

Fig. 8(a) illustrates the hypocentral depth distribution for the three considered catalogues. The differences among these three data sets appear to be partially biased by the fact that they do not cover the same events of the crisis. Indeed, most of the events for which cepstral depths are determined are located in the northern part of the aftershock area, below the High Himalaya range, while most of the events with good local depths are inside the Nepal national network. Given that teleseismic depth phases are difficult to identify for shallow events (0-6 km depth), our final data set is therefore composed by a smaller number of such shallow events. This results in a higher depth average value. In the $\mathrm{N} 108^{\circ}$ cross-section (Fig. $8 \mathrm{~b}$ ), shallow events are only observed in the local catalogue. However, when disregarding these events, the major part of the seismicity remains consistent between catalogues. A bias coming from the velocity model is also possible. A topographic effect could also create a bias of $1-2 \mathrm{~km}$ on the depth estimation as the estimation 
Table 1. Confrontation of the depths (in kilometres) for aftershocks studied in Adhikari et al. (2015) and Bai et al. (2016) that meet all three criteria for cepstral depth determination (this study).

\begin{tabular}{lccccccc}
\hline $\begin{array}{l}\text { Event } \\
\text { number }\end{array}$ & Lat $\left(^{\circ}\right)$ & Lon $\left(^{\circ}\right)$ & $\begin{array}{c}\text { Origin } \\
\text { time }\end{array}$ & $\begin{array}{c}\text { Cepstral } \\
\text { depth }\end{array}$ & $\begin{array}{c}\text { Local } \\
\text { depth }\end{array}$ & $\begin{array}{c}\text { RSTT } \\
\text { depth }\end{array}$ & $\begin{array}{c}\text { Regional depth } \\
\text { (Bai } \text { et al. 2016) }\end{array}$ \\
\hline $\mathbf{1}$ & 27.824 & 85.802 & 2015 April 25 21h07 & 12.2 & 10 & 19 & 18 \\
$\mathbf{2}$ & 27.795 & 85.997 & 2015 April 26 08h40 & 11.6 & 25 & 21.9 & 14.7 \\
$\mathbf{3}$ & 27.565 & 85.738 & 2015 April 26 22h32 & 12.3 & 10 & 13.6 & 20.1 \\
$\mathbf{4}$ & 27.692 & 85.928 & 2015 May 02 21h44 & 11.7 & 10 & 13.8 & 12.4 \\
\hline
\end{tabular}

of the reflection point can be incorrect. Despite these sources of uncertainties, the depth of the seismic events between 10 and $15 \mathrm{~km}$ is relatively consistent.

\section{DISCUSSION}

The teleseismic depths determined for the 61 seismic events studied with the cepstral approach are relatively shallow $(13.1 \pm 3.9 \mathrm{~km})$. In this study, their locations are compared to other methods and catalogues. We find them to be consistent on average with the study of Bai et al. (2016) (i.e. regional average depths at $12.9 \mathrm{~km}$ ) but deeper on average than the results coming from the local depth estimation (i.e. around $10-11 \mathrm{~km}$ ). The comparison between the local and teleseismic depth estimations is difficult as only four events are in common in the two data sets (Table 1). This is due to two main reasons: (1) depth phases generated by shallow events are not detected at teleseismic distances and (2) most of the teleseismic events for which depth estimations were determined are located outside the Nepalese seismic network, mainly to the north of the rupture. Because of these differences, we find a great advantage to combine local and teleseismic methods. It indeed allows us to constrain a widest range of earthquake types and locations. Globally, the uncertainties on depth estimations depend on phase picking, inversion process, phase identification and on the velocity model considered. These uncertainties are difficult to precisely characterize for all methods but they should remain large (above $\pm 5 \mathrm{~km}$ ). The differences in the depth estimations observed for the four common events in the different catalogues (Table 1) that we assume to be well constrained, illustrate these uncertainties.

These observations let us ascertain that the aftershocks are clustered in a narrow band at depths $\sim 10-15 \mathrm{~km}$ (see Figs $8 \mathrm{~d}$ and 9 ). This band could even be narrower than $5 \mathrm{~km}$ given the uncertainties on the depth estimations. This suggests that most of the aftershocks could be located within the MHT shear zone or slightly above it in its hangingwall.

Indeed a depth of 10-15 km corresponds typically to the depth of a low velocity zone (LVZ) resolved below the High Himalayan range by the analysis of receiver functions (e.g. Schulte-Pelkum et al. 2005; Nábelek et al. 2009; Caldwell et al. 2013; Duputel et al. 2016). This LVZ is associated with the MHT shear zone, which is also inferred there from the geometry of its creeping section constrained by the geodetic data available (e.g. Jackson \& Bilham 1994; Grandin et al. 2012; Elliott et al. 2016) and suggested by the location of the mid-crustal seismicity during the interseismic period (e.g. Pandey et al. 1995; Monsalve et al. 2008; Hayes et al. 2015). Whether part of the seismicity is also generated in the hangingwall of the MHT shear zone is unclear given both uncertainties on the depths (1) of the aftershocks and (2) of the MHT fault.

The uncertainties on the depths also prevent us to resolve the position and height of the mid-crustal ramp of the flat/ramp thrust system, which is a ramp involved in the underplating of the Lesser Himalayan duplex and uplift at the front of the range (e.g. Lavé \& Avouac 2001; Bollinger et al. 2006; Robinson \& Martin 2014). The cross-sections through the aftershocks do not reveal any clear evidence of such a ramp in the western part of the tectonic system (Fig. 9a) suggesting that it is smaller than $5 \mathrm{~km}$ or located at the periphery of the aftershock cluster.

In the meantime, the cross-sections through the easternmost clusters of aftershocks (Fig. 9b) reveal that the seismicity to the north is scattered through a wider range of depths suggesting possible lateral variations of the hypocentral depths. This discrepancy could be related either to lateral structural variations within the easternmost $70 \mathrm{~km}$ projected on the cross-section or to the presence of a seismic activity in the footwall and/or hangingwall of the thrust system and need further descriptions.

In order to solve that issue, we have a closer look at the seismicity located at the northeastern end of the rupture, beyond the region where slip died off abruptly on April 25, a region which partially ruptured on May 12 during an $M_{\mathrm{w}} 7.3$ event (region A on Figs 1 and $9 \mathrm{~b}$ ). The depths of the seismic events there are determined at $13.7 \pm 4.2 \mathrm{~km}$ for teleseismic analyses and $13.4 \pm 5.3 \mathrm{~km}$ for RSTTISC locator. These depths are approximately $2 \mathrm{~km}$ deeper $(1.3 \mathrm{~km}$ for teleseismic and $3.5 \mathrm{~km}$ for RSTT-ISC locator) than within the western and south-eastern sections where the seismicity develops at $12.4 \pm 3.6 \mathrm{~km}$ for teleseismic and $9.9 \pm 3.4 \mathrm{~km}$ for RSTT-ISC locator. The fact that both local and teleseismic studies, which rely on independent data/methods/velocity models point to similar results leave us confident that these deeper events are not due to a bias coming from the inversion process and phase pickings/identifications. The apparent depth variation might be either related (1) to a variation of crustal velocities or (2) to a true variation of the depth of the tectonic structures activated. Indeed, a velocity reduction of 10-15 per cent over the upper $10-15 \mathrm{~km}$ at the northeastern end of the region affected by the main rupture could potentially explain the $2 \mathrm{~km}$ difference in average depths. However, a velocity reduction alone seems not well adapted to explain the high range of depths estimated in the area, where we would then expect a global shift of the seismicity. Furthermore, we expect to encounter similar seismic velocities in this area at the northern end of a structural window on the Lesser Himalayan rocks and within the similarly exhumed region West of the Katmandu Klippe given the similar nature of the Lesser Himalayan metasediments. We therefore prefer to relate the apparent depth variations to lateral structural variations. Effectively, the basal decollement of the MHT could be stepping down toward east which is consistent with the observation made by Hayes et al. (2015), who found that deeper slip near the eastern extent of the rupture can be explained by the geodetic slip model. Lateral change of the decollement could be coherently related to the observed lateral variations of the Himalayan duplex (Schelling \& Arita 1991; Robinson \& Martin 2014).

A change of the depth of the decollement should be associated with the presence of a lateral ramp or tear fault. Studying the 
(a)

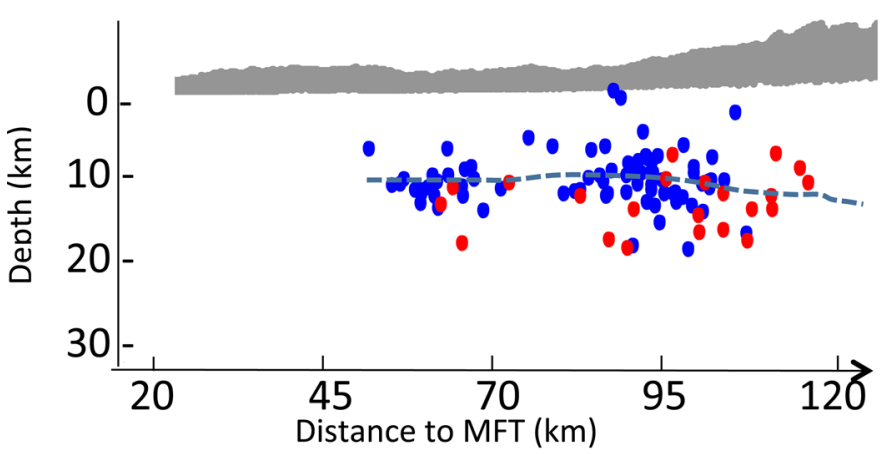

(b)

\section{Cross section N18 East}

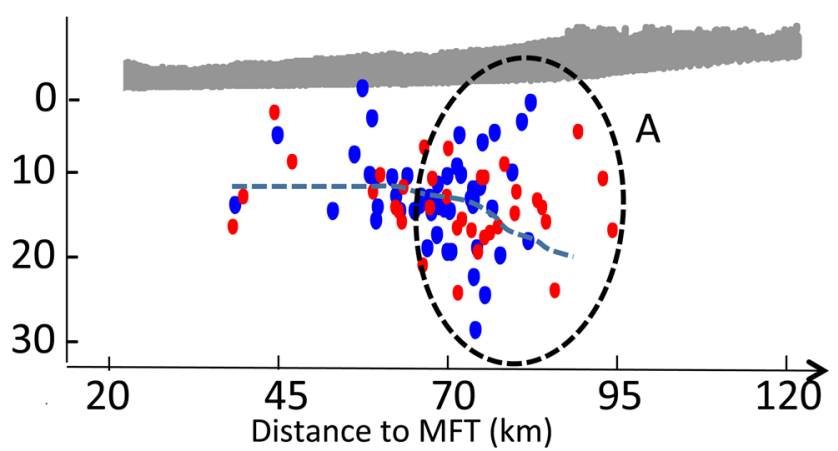

(c)

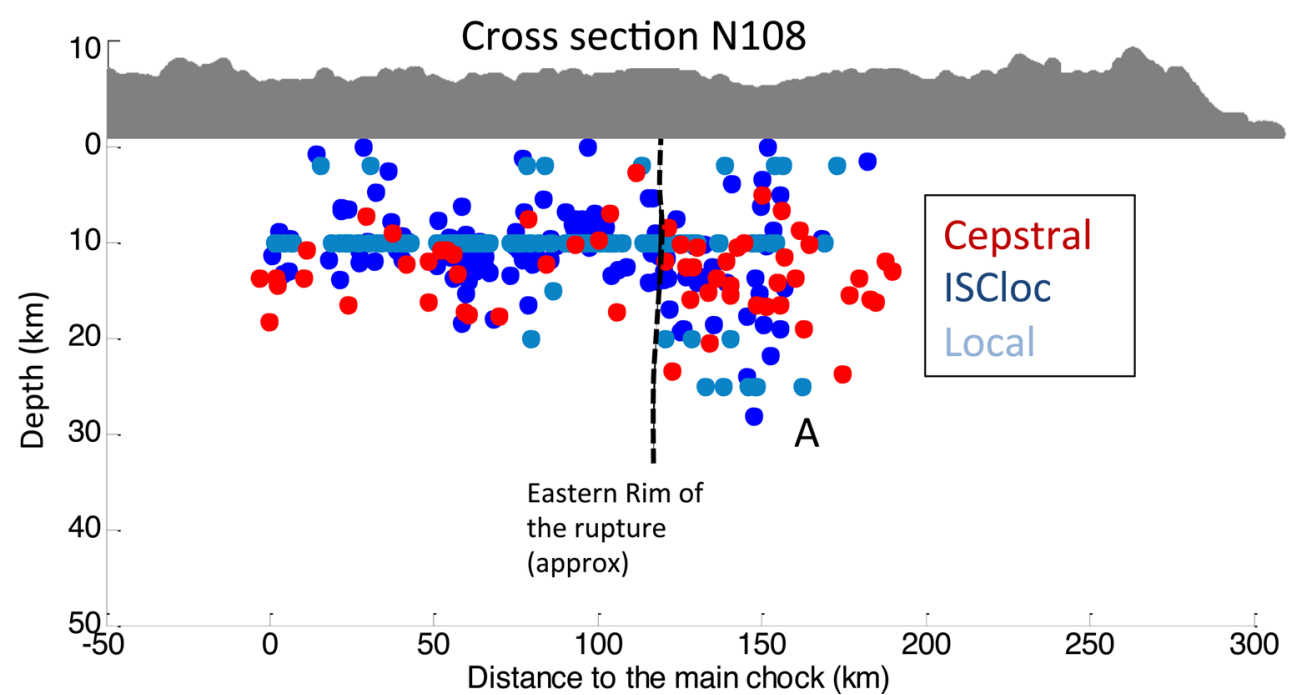

Figure 9. (a) Estimated depths along the N18 cross-section, for the ISC-loc relocated (blue) and the teleseismic (red) analyses for events in the western part of the rupture up to $100 \mathrm{~km}$ from the main shock. (b) Same cross-section but for the events in the eastern part (>100 km). (c) Estimated depths along the $\mathrm{N} 108^{\circ}$ cross-section, for the ISC-loc relocated events (blue), the teleseismic analysis (red) and for the constrained depth estimations extracted from the local catalogue (light blue).

focal mechanisms in this area could reveal its seismic activation. If an estimation of the focal mechanism through the use of the teleseismic recordings seems challenging, the comparison for different azimuths between the direct $P$-wave radiation and the $P$-coda radiation (dominated either by $p P, s P$, or other reflections, for instance PcP for the array ILAR; Fig. S3, Supporting Information) shows a clear difference of radiation for events in the transition zone between the eastern and western part (Fig. S3, Supporting Information). This radiation pattern difference is probably due to a change of mechanism, which seems to support the hypothesis of a change of the geometry of the tectonic structures activated at the eastern rim of the rupture.

Moreover, the region where the basal decollement step-down is suspected to coincide exactly with the area where the coseismic slip died off dramatically on April 25, drawing a coseismic slip embayment to the south (Fig. 1). Seventeen days later, that northeastern section did partially fail during the May $12 M_{\mathrm{w}} 7.3$ rupture, leaving a narrow region of low cumulative slip in between (Fig. 1). The segmentation of the rupture along the MHT might therefore be related to the presence of lateral structural variations acting as an impediment along the fault. This impediment might have acted as a barrier to the April 25 Gorkha earthquake rupture propagation, a rupture which abruptly stopped there to the east. This barrier might be a persistent rupture initiation or termination point. Indeed, in 1833, the large M7.5-7.9 earthquake appeared similar to the 2015 Gorkha earthquake (Martin et al. 2015; Bollinger et al. 2016), with a mesoseismal zone abutting in the area. We suspect that the rupture of the great M8.2 1934 earthquake terminated in the same area given the extent of its surface ruptures and the extension of its mesoseismal zone (Sapkota et al. 2013; Bollinger et al. 2016). Whether this segmentation is associated with the variations of the frictional properties of the seismogenic zone and interseismic coupling, in a similar way as along subduction zones (e.g. Métois et al. 2012; Béjar-Pizarro et al. 2013) is still an issue: the coupling estimated through this area is associated with significant uncertainties (20-60 per cent, for example, Ader et al. 2012 and Grandin et al. 2015) and can hardly be used to confirm a possible relationship between a coupling variation and the presence of a tectonic impediment to ruptures along strike the MHT.

Complementary studies of the elastic coupling, focal mechanisms and local velocity models, within this specific area at the eastern rim of the Gorkha earthquake rupture will be necessary to investigate further the segmentation of the MHT along strike and its persistent influence on past and future earthquake rupture termini. 


\section{ACKNOWLEDGEMENTS}

We acknowledge the constructive reviews of Dmitry Storchak and Alireza Alinaghi, the editor Frank Krueger and the editorial handling. We also acknowledge the CTBTO (Comprehensive Test Ban Treaty Organization) to provide data and funding. We thank the Nepalese DMG (Department of Mines and Geology) for access to their bulletin catalogue with phases picked. We are thankful to Sophie Merrer for providing the relocated catalogue used in this study and Roser Hoste-Colomer for her useful help to well understand and interpret the tectonic and geological features of the area, as well as for providing figures and supports. This study has been conducted at the LRC (Laboratoire Yves Rocard, Laboratoire de Recherche Conventionné).

\section{REFERENCES}

Ader, T.J., Ampuero, J \& Avouac, J., 2012. The role of velocity-neutral creep on the modulation of tectonic tremor activity by periodic loading, Geophys. Res. Lett., 39(16), L16310 doi:10.1029/2012GL052326.

Adhikari, L.B. et al., 2015. The aftershock sequence of the April 252015 Gorkha-Nepal earthquake, Geophys. J. Int., 203, 2119-2124.

Avouac, J.P., Meng, L., Wei, S., Wang, T. \& Ampuero, J.P., 2015. Lower edge of locked Main Himalayan Thrust unzipped by the 2015 Gorkha earthquake, Nat. Geosci., 8, 708-711.

Bai, L., Liu, H., Ritsema, J., Mori, J., Zhang, T., Ishikawa, Y. \& Li, G., 2016. Faulting structure above the Main Himalayan Thrust as shown by relocated aftershocks of the $2015 M_{\mathrm{w}} 7.8$ Gorkha, Nepal, earthquake, Geophys. Res. Lett., 43, 637-642.

Béjar-Pizarro, M., Socquet, A., Armijo, R., Carrizo, D., Genrich, J. \& Simons, M., 2013. Andean structural control on interseismic coupling in the North Chile subduction zone, Nat. Geosci., 6(6), 462-467.

Bollinger, L., Henry, P. \& Avouac, J.P., 2006. Mountain building in the Nepal Himalaya: thermal and kinematic model, Earth planet. Sci. Lett., 244, 58-71.

Bollinger, L., Tapponnier, P., Sapkota, S.N. \& Klinger, Y., 2016. Slip deficit in central Nepal: Omen for a repeat of the $1344 \mathrm{AD}$ earthquake?, Earth Planets Space, 68, 1-12.

Bondár, I. \& Storchak, D., 2011. Improved location proceduress at the International Seismological Centre, Geophys. J. Int., 186, 1220-1244.

Bondár, I., Myers, S.C., Engdahl, E.R. \& Bergman, E.A., 2004. Epicenter accuracy based on seismic network criteria, Geophys. J. Int., 156, 483496.

Bouchon, M., 1976. Teleseismic body wave radiation from a seismic source in a layered medium, Geophys. J. R. astr. Soc., 47, 515-530.

Caldwell, W.B., Klemperer, S.L., Lawrence, J.F., Rai, S.S. \& Ashish, P., 2013. Characterizing the Main Himalayan Thrust in the Garhwal Himalaya, India with receiver function CCP stacking, Earth planet. Sci. Lett., 367, $15-27$.

Denolle, M.A., Fan, W. \& Shearer, P.M., 2015. Dynamics of the 2015 M7.8 Nepal earthquake, Geophys. Res. Lett., 42(18), 7467-7475.

Duputel, Z., Vergne, J., Rivera, L., Wittlinger, G., Farra, V. \& Hetényi, G., 2016. The 2015 Gorkha earthquake: a large event illuminating the Main Himalayan Thrust fault, Geophys. Res. Lett., 43, 2517-2525.

Elliott, J.R., Jolivet, R., González, P.J., Avouac, J.P., Hollingsworth, J., Searle, M.P. \& Stevens, V.L., 2016. Himalayan megathrust geometry and relation to topography revealed by the Gorkha earthquake, Nat. Geosci., 9, 174180.

Engdahl, E.R., van der Hilst, R. \& Buland, R., 1998. Global teleseismicearthquake relocation with improved travel times and procedures for depth determination, Bull. seism. Soc. Am., 88, 722-743.

Geiger, L., 1912. Probability method for the determination of earthquake epicenters from the arrival time only, Bull. St. Louis Univ., 8, 60-71.

Gomberg, K., Shedlock, K. \& Roecker, S., 1990. The effect of $S$-wave arrival times on the accuracy of hypocenter estimation, Bull. seism. Soc. Am., 80, $1605-1628$.
Grandin, R., Doin, M.P., Bollinger, L., Pinel-Puysségur, B., Ducret, G., Jolivet, R. \& Sapkota, S.N., 2012. Long-term growth of the Himalaya inferred from interseismic InSAR measurement, Geology, doi:10.1130/G33154.1.

Grandin, R., Vallée, M., Satriano, C., Lacassin, R., Klinger, Y., Simoes, M. \& Bollinger, L., 2015. Rupture process of the $M_{\mathrm{w}}=7.92015$ Gorkha earthquake (Nepal): insights into Himalayan megathrust segmentation, Geophys. Res. Lett., 42(20), 8373-8382.

Hayes, G.P., Briggs, R.W., Barnhart, W.D., Yeck, W.L., McNamara, D.E., Wald, D.J. \& Marano, K., 2015. Rapid characterization of the $2015 M_{\mathrm{w}}$ 7.8 Gorkha, Nepal, earthquake sequence and its seismotectonic context, Seism. Res. Lett., 86(6), 1557-1567.

Jackson, M.E. \& Bilham, R., 1994. 1991-1992 GPS measurements across the Nepal Himalaya, Geophys. Res. Lett., 21(12), 1169-1172.

Kennett, B.L.N. \& Engdahl, E.R., 1991. Travel times for global earthquake location and phase association, Geophys. J. Int., 105, 429-465.

Lavé, J. \& Avouac, J.P., 2001. Fluvial incision and tectonic uplift across the Himalayas of central Nepal, J. geophys. Res., 106(B11), 26 56126591.

Letort, J., Guilbert, J., Cotton, F., Bondár, I., Cano, Y. \& Vergoz, J., 2015. A new, improved and fully automatic method for teleseismic depth estimation of moderate earthquakes $(4.5<\mathrm{M}<5.5)$ : application to the Guerrero subduction zone (Mexico), Geophys. J. Int., 201(3), 1834-1848.

Letort, J., Vergoz, J., Guilbert, J., Cotton, F., Sebe, O. \& Cano, Y., 2014. Moderate earthquake teleseismic depth estimations: new methods and use of the Comprehensive Nuclear-Test-Ban Treaty Organization network data, Bull. seism. Soc. Am., 104, 593-607.

Lindsey, E., Natsuaki, R., Xu, X., Shimada, M., Hashimoto, H., Melgar, D. \& Sandwell, D., 2015. Line of sight deformation from ALOS-2 interferometry: $M_{\mathrm{W}} 7.8$ Gorkha earthquake and $M_{\mathrm{W}} 7.3$ aftershock, Geophys. Res. Lett., 42, 6655-6661.

Lundquist, G. \& Cormier, V., 1980. Constraints on the absorption band model of Q, J. geophys. Res., 85, 5244-5256.

Martin, S.S., Hough, S.E. \& Hung, C., 2015. Ground motions from the 2015 $M_{\mathrm{w}} 7.8$ Gorkha, Nepal, earthquake constrained by a detailed assessment of macroseismic data, Seismol. Res. Lett., 86(6), 1524-1532.

Métois, M., Soquet, A. \& Vigny, C., 2012. Interseismic coupling, segmentation and mechanical behavior of the central Chile subduction zone, J. geophys. Res., 117(B3), B03406, doi:10.1029/2011JB008736.

Monsalve, G., Sheehan, A., Rowe, C. \& Rajaure, S., 2008. Seismic structure of the crust and the upper mantle beneath the Himalayas: evidence for eclogitization of lower crustal rocks in the Indian Plate, J. geophys. Res., 113, B08315, doi:10.1029/2007JB005424.

Mueller, C.S., 1985. Source pulse enhancement by deconvolution of an empirical Green's function, Geophys. Res. Lett., 12, 33-36.

Myers, S.C. et al., 2010. A crust and upper mantle model of Eurasia and North Africa for Pn travel-time calculations, Bull. seism. Soc. Am., 100, 640-656.

Nábelek, J. et al., 2009. Underplating in the Himalaya-Tibet collision zone revealed by the Hi-CLIMB experiment, Science, 325, 1371-1374.

Pandey, M.R., 1985. Seismic model of central and eastern lesser Himalaya of Nepal, J. Nepal Geol. Soc., 3(1-2), 1-11.

Pandey, M.R., Tandukar, R.P., Avouac, J.P., Lavé, J. \& Massot, J.P., 1995. Interseismic strain accumulation on the Himalayan Crustal Ramp (Nepal), Geophys. Res. Lett., 22(7), 751-754.

Pearce, R.G. \& Rogers, R.M., 1989. Determination of earthquake moment tensors from teleseismic relative amplitude observations, J. geophys. Res., 94(B1), 775-786.

Robinson, D.M. \& Martin, A.J., 2014. Reconstructing the Greater Indian margin: a balanced cross section in central Nepal focusing on the Lesser Himalayan duplex, Tectonics, 33(11), 2143-2168.

Sapkota, S.N., Bollinger, L., Klinger, Y., Tapponnier, P., Gaudemer, Y. \& Tiwari, D., 2013. Primary surface rupture of the great Himalayan earthquakes of 1934 and 1255, Nat. Geosci., 6, 71-76.

Schelling, D. \& Arita, K., 1991. Thrust tectonics, crustal shortening, and the structure of the far-eastern Nepal Himalaya, Tectonics, 10(5), 851862. 
Schulte-Pelkum, V., Monsalve, G., Sheehan, A., Pandey, M.R., Sapkota, S., Bilham, R. \& Wu, F., 2005. Imaging the Indian Subcontinent beneath the Himalaya, Nature, 435, 1222-1225.

Storchak, D.A., Harris, J. \& Bondar, I., 2011. CTBTO Contribution to the global earthquake data collection: a view from the International Seismological Centre (ISC), in ISS Meeting, Hofburg Palace, Vienna, Austria, 10 June 2011. Abstract number T5-06, p. 3.

Vallée, M., 2004. Stabilizing the empirical Green function analysis: development of the projected Landweber method, Bull. seism. Soc. Am., 94, 394-409.

Vallée, M., Bouchon, M. \& Schwartz, S.Y., 2003. The 13 January 2001 El Salvador earthquake: a multidata analysis, J. geophys. Res., 108, 22032208.

\section{SUPPORTING INFORMATION}

Additional Supporting Information may be found in the online version of this paper:

Figure S1. (a) and (b) show 1-3 Hz bandpass filtered teleseismic records of the Gorkha aftershocks from arrays TORD and FINNES, respectively. The traces are normalized and aligned according to the average $P$-wave arrivals picked in each array, and sorted according to their estimated depth found in this study. The blue lines are the theoretical arrival times of the $p P$ phases (for TORD) and the red lines for the $s P$ phases (FINNES).

Figure S2. Beam for (a) FINNES and (b) TORD for the event 1 in Table 1. The theoretical arrival time of the $s P$ phase detected by the cepstrum analysis for the depth of $12.2 \mathrm{~km}$ is represented by the blue line and the theoretical arrival time for the $p P$ phase detected on TORD by the red line. The red and blue dashed lines are, respectively, the theoretical arrival times for $p P$ and $s P$ arrivals for an event at a depth of $19 \mathrm{~km}$ (RSTT solution).

Figure S3. Recordings of the aftershocks, filtered between 1 and $3 \mathrm{~Hz}$, for three arrays (a) TORD, (b) FINNES and (c) ILAR (Alaska). Recordings of the stations of the arrays showing a clear $P$-wave arrival are picked and aligned according to this $P$-wave arrival (at around $2 \mathrm{~s}$ ). Events are then sorted from left to right according to their distance to the main shock. The recordings for the events at the eastern rim of the rupture are inside the dashed blue lines. Note that despite good signal-to-noise ratio, the array ILAR has not been used for depth estimation because of the possible presence of corereflected waves (PcP) around $5 \mathrm{~s}$ after the $P$ arrival. (d) $-(\mathrm{f})$ are the synthetics, respectively, for TORD, FINNES and ILAR, for a source at $15 \mathrm{~km}$ deep, with a source duration of $1 \mathrm{~s}$, for the different focal mechanisms shown in (g). For transform faults, the $P$-wave arrivals are weak for the three stations, but inverse faults show strong $P$ arrivals.

Table S1. Teleseismic depth estimations (this study), locations and magnitudes $M_{\mathrm{L}}$ are taken from Adhikari et al. (2015).

(http://gji.oxfordjournals.org/lookup/suppl/doi:10.1093/gji/ ggw364/-/DC1)

Please note: Oxford University Press is not responsible for the content or functionality of any supporting materials supplied by the authors. Any queries (other than missing material) should be directed to the corresponding author for the paper. 